\title{
Study on the Humanistic Thoughts and Spirit of Confucianism in Tang and Song Literature
}

\section{Xinning Fang}

Northwest Normal University, College of Chinese Language and Literature, Lanzhou, Gansu 730070

Keywords: humanistic thoughts; Confucianism spirit; Tang and Song Literature

\begin{abstract}
In today's multi-polarized development of Confucianism and the reciprocity of each other, it is an extremely necessary and extremely meaningful work to explore and establish the ontological morphology of Confucianism, and humanistic Confucianism should become the ontological form of Confucianism today.
\end{abstract}

\section{Introduction}

In recent years, the study of scholars in the Tang and Song Dynasties, Confucianism in the Tang and Song Dynasties continued to deepen, and scholars have increasingly focused on the inclusion of scribes in the category of Confucian studies. They realized that to increase the depth of Confucianism research, we should not only focus on the traditional meaning of philosophers and thinkers, but also need to pay attention to the active role of the "Literati" in the construction of Confucianism and cultural transformation. Only in this way, the understanding of the transformation of the Tang and Song dynasties can be called comprehensive, and the excavation of the literati's character and cultural connotation can be deepened. In view of this, the author will sort out the relevant research results in this area in order to benefit from similar research.

Traditional Chinese ideology and culture is essentially a kind of knowledge about "human", and the most important characteristic is to attach importance to the reality of people and life. Confucianism, as the mainstream of Chinese culture, focuses more on exploring the nature of human beings, human nature, human values, human ideals, the realization of ideal personality, and the life and death and freedom of human beings. Confucianism formed its distinctive humanistic spirit of paying attention to the present life in its exploration of these issues. The fundamental purpose of the Chinese people's belief in the spirits is not to leave the world but to seek blessings for the happiness of the world. The immortal life pursued by Taoism seems to be refined and refined. It is actually nothing more than the idealization and infinite extension of the present life. After the Indian Buddhism, which saw life as a sea of misery and detachment of life and death, was spread to China, it was conceived by many men and women as blessings for the peace of this life or the religion of the world's future. It also brought to light the Chinese people's view of life in the real life. There is a view that traditional culture emphasizes group rather than individuality. Therefore, the lack of subject consciousness in traditional culture and the lack of affirmation of the subject value, especially the philosophy of Confucian life, are also the pursuit of social values at the expense of individual values. Confucianism explored and presented its own answers to problems such as human nature, human values, and human fulfillment through a tortuous path under the specific social and historical conditions of feudal society in China. To explore the revival of Confucianism in the Tang Dynasty, Han Yu, Liu Zongyuan, Li Yu, Bai Juyi, and Yuan Zhen have always been the focus of attention. If the dismissal of Li Bai's ideological ideals of "achievement and retirement" declares the end of personal idealism, then the rise of this group of people behind him means the formation of a collective utilitarian Confucian view. Xu Jiasheng sorted out, explained, and analyzed Han Yu's Taoism and Taoism from two angles: ideological history and religious theory. He believed that Han Yu's words "Confucian Taoism" were a combination of self-cultivation, aspirational approach, and transcendence. The "Orthodox Pedigree" is a continuation system of the theoretical thinking of pursuing the integration of rationality in concrete time and space [5]. Zhou Jing paid special attention to the systematic study and detailed analysis of Han Yujing's studies, 
which he paid less attention to in the academic world. He believed that Han Yuli's Taoist Confucianism, approved the old teachings of Buddha, opened the new method of transmitting the Confucian classics, and respected the classics of "University" and "Mencius". As a way to give birth to the development of the Neo-Confucianism of Song and Ming Dynasties, it provided a direction for thinking; it laid an important foundation for classical selection of the Song and Ming Neo-Confucianism and theoretical construction [6]. Han Lihua believes that Li Zhi's "Refolding Book" has constructed a philosophical ideology system with "honesty" as the core category, and has thus contributed to the conversion of Confucianism from "Jing Studies" to "Ren Xue" [7]. The duality of the Confucian philosophy of life lays the basic framework in the pre-Qin period of Confucius and Mencius. The founder of Confucius, Confucius, lived in the late spring and autumn period of the great transformation of society. His benevolence and rituals, which were put forward on the basis of his predecessors' thoughts, clearly affirmed the nature and value of man, and discussed the realization of the nature and value of man. , laid the basic characteristics of the Confucian humanistic spirit. In the ethic of the group, the Confucian observes the essence, value, and realization of the individual's individual life. On the basis of the affirmative person, it regulates human behavior with love and righteousness, and raises this to the height of realizing the human nature. This is meaningful for improving everyone's character and ensuring the healthy operation of society. This also provides a humanistic value basis for Confucianism in the spirit of WTO entry.

\section{Tortuous Development of Humanistic Spirit of Confucianism}

Confucius created the dual nature of Confucianism's emphasis on human beings and emphasis on the relationship between human beings, which made the development of Confucianism always show a dynamic swing between the two, leading to this kind of swinging Confucianism and humanism. The internal requirements for the development of the spirit itself also have the external impacts of social changes, zeitgeist ideological trends and various other ideological doctrines. When the ethical norms of coordinating society, up and down, and all kinds of interpersonal relations are not only described as the nature of human beings, but also strengthened into the moral guidelines of the "Three Programs and Five Normals" and the intricacies with the authoritarian centralized rule, the realization of Confucianism about human beings. The ideal has become a kind of paper talk. Since the Han Dynasty, the emphasis on Confucianism on human beings has gradually been submerged in a strong political relationship of human relations. Dong Zhongshu's proposal of "abandoning 100 families and exclusively advocating Confucianism" was adopted by Han Wudi. "Bai Hutong" was specifically designated as the "three principles and six disciplines" as the eternal ethical norms and the highest political norms. The Confucian ethics began to be theological It is a well-known moral education, and it has become a code of conduct that everyone in society must follow. Although the construction of this guideline is based on the realization of human needs, it has been bound to human nature. Individuals are required to absolutely obey the needs of society, and the needs of society are actually the stability of a certain feudal dynasty. The need for an orderly hierarchy of feudalism essentially becomes the political will of the ruler. Confucianism pays attention to the humanistic spirit of the present-day life, on the one hand, it shows its emphasis on human value and human relations, on the other hand, it also shows through its emphasis on positive entry into the world and the philosophical discussion on human nature. The typical Chinese Buddhist sect Zen Buddhism destroys the worship of external authority such as Buddha and emphasizes the autonomy of everyone. On the other hand, it melts and dissolves the ideals in the current real life. Between dressing and eating, he advocated "the Dharma in the world, not depart from the world," "Altar Scriptures", and further thought that "who cares to keep their peace, why do they use the practice of meditation; grace will filial their parents, righteousness up and down Compassion, letting you be respectful and humble, and tolerating evil, "'Altar Suspects", and even that "worldly rule of Dharma, Dharma is the worldly method", "Dahui Pujue Chan Master Quotations," vol.27, "Sandism Nothing to Stand Dharma "'The Complete Works of Master Lushan Tour" volume 45. The reason why Buddhism, which was born after the birth, finally turned to China after entering the WTO and facing life, is inseparable from the influence of Confucianism. 
From the perspective of exploring human values and pursuing the realization of human relations in human relations, Confucianism has evolved into a feudal society and has evolved over the millennia of its theoretical evolution. Its pro-independence, youthful and orderly relationship has been strengthened as a moral dogma. , And become a kind of politics combined with politics, not only led to the loss of its humanistic spirit, but also made it a fig leaf of the ruler's hypocrisy, and became the aggressor of the ruler's maintenance of dictatorship and murder of human nature. When the Chinese people fought in the struggle against imperialism and feudalism, they naturally pointed to the Confucianism that represented the feudal ideology. They hoped to express the negation and criticism of traditional old politics and the old morality through the comprehensive liquidation of Confucianism. The great ups and downs of Confucianism in the 20th century were both caused by the impact of social and political development on Confucianism and closely related to people's understanding of the duality of Confucianism. When the Revolution of 1911 overthrew the system of imperialism, the establishment of the government of the Republic of China actually negated the status of Confucianism as the guiding ideology of ideology. However, Yuan Shikai wanted to restore the emperor and also played a farce to worship Confucianism. Kang Youwei and others also claimed to honor the Confucian classics, and even established the so-called "Confucian Church", proposing to "define Confucianism as a state religion." These adverse actions have led to the vigorous rise of the May Fourth New Culture Movement. The long history of Confucianism as the mainstream of Chinese traditional culture, after all, contains something of value to human beings. The theoretical doctrine has certain innovations, but because they mainly reconstructed Confucianism in philosophy, they lacked a series of social problems brought about by associating Confucianism with the real environment and responding to the rapid development of modern politics and economy. They lacked the philosophy of Confucian life. The dialectical thinking of duality responds to how to rebuild new human relations in modern society and caring for the survival of every individual life. Therefore, although they have constructed a broad and profound, abstract and mysterious Neo-Confucian system, they can only The academic community has spread and failed to exert a great influence on the entire social culture. The vitality and modern value of the humanistic spirit of Confucianism also needs our excavation, transformation and innovation activities. Traditional Confucianism explores and solves life problems under the bondage of feudal autocracy, and it has always been difficult to avoid the paradox between personal values and social etiquette. It pursues the realization of personal ideals in social human relations, but it eventually leads to people. Bondage. Only by thoroughly breaking the feudalism can we really end the tragedy and save what is meaningful and valuable to modern society and life in Confucianism.

In recent years, Confucianism in the Tang Dynasty has gradually become the focus. When studying the significance of cultural transformation in this transitional period, in addition to discovering new problems, scholars also pay attention to changing perspectives and adjusting ideas to conduct in-depth discussions on old issues. Lan Cui emphatically combed the development of the study of the Meng scholars in the Tang dynasty. He believed that the main characterization of the Meng Xue in the early Tang dynasty was the enlistment of the Mencius theory; the Tang dynasty was transformed into the spiritual inheritance and action of the Mencius ideology; Note the increase of Meng, Xie Meng, and topical discussion; the Late Tang Dynasty inherited the atmosphere of Zhongyu Tang and Han Yuzun, and promoted the promotion of Mencius in the Northern Song Dynasty. During this period, Lin Shensi's “Continued Mencius” enriched Meng Xue's study ideologically. In terms of form, it also revised the text of the Song and Confucianism, and said that the Scriptures opened the infinite teaching. Cheng Yuying believes that the Tang Dynasty's cultural ambitions have formed an open and ambitious feature, which has a lot to do with the poverty of Confucianism in the Tang Dynasty. However, Buddhas and Dao require people to be separated from reality and call for a home, which constitutes a huge threat to the economic basis of feudal rule. It is also doomed that the two cannot replace Confucianism and assume responsibility for social governance. By the middle and late Tang Dynasty, the three families had begun to seek coordination and integration in order to adapt to the needs of the political system and to consider their own survival and development. This has laid a good ideological foundation for Confucianism and the 
integration of the three religions (50). Liu Guangyu discussed the development and characteristics of Confucianism in Sui and Tang dynasties from the evolution of the study of Confucian classics in the Sui and Tang dynasties, the development of Confucianism and the relationship between the three religions and academic thought. He believed that Confucianism in Tang dynasty was a transition between Sinology and Song Studies. It was during this period that the major turn of events began.

\section{Conclusion}

Our transformation of society today is to create better conditions for solving people's problems and realizing people's freedom and liberation. At the same time, it is also the end of the historical tragedy of Confucianism and the restoration and development of the humanistic spirit of Confucianism.

\section{References}

[1] Wang Liping. The classics of the Chinese literati hierarchy and Confucian literature [J]. Journal of Yanshan University, 2010,(4):41.

[2] Hua Jun. Road to rejuvenation: practical inclination and reflection in traditional cultural rejuvenation [J]. Changbai Academic Journal, 2008,(5):14.

[3] Liu Chaoqian. Li Bai's philosophical and aesthetic knowledge [J]. Social Sciences Research, 2017, (2): 81.

[4] Fu Shaoliang. Li Bai's sexual consciousness and tragedy mentality [J]. Journal of Shaanxi Normal University, 2022, (1): 55. 